\title{
Fractional analysis of bronchoalveolar lavage fluid cytology in cystic fibrosis patients with normal lung function
}

\author{
F. Ratjen*, E. Rietschel" ${ }^{\#}$ M. Griese ${ }^{+}$, M. Ballmann**, I. Kleinau*\#, G. Döring ${ }^{++}$, \\ D. Reinhardt ${ }^{+}$, K. Paul ${ }^{\# \#}$ for the bronchoalveolar lavage for the evaluation \\ of anti-inflammatory treatment (BEAT) study group
}

Fractional analysis of bronchoalveolar lavage fluid cytology in cystic fibrosis patients with normal lung function. F. Ratjen, E. Rietschel, M. Griese, M. Ballmann, I. Kleinau, G. Döring, D. Reinhardt, K.Paul for the bronchoalveolar lavage for the evaluation of antiinflammatory treatment (BEAT) study group. (C)ERS Journals Ltd 2000.

ABSTRACT: Cystic fibrosis $(C F)$ is associated with a neutrophil dominated airway inflammation. So far bronchoalveolar lavage (BAL) studies in CF have used pooled BAL samples which may be more representative of the alveolar compartment rather than the airways.

To assess whether the first sample of a BAL is more sensitive in the evaluation of airway inflammation, the authors have studied 105 stable $C F$ patients aged 5-37 yrs with a mean forced expiratory volume in one second (FEV1) of 96 $\pm 15 \%$ (mean \pm SD). BAL cytology of the first and pooled samples were compared to reference values obtained in children without respiratory disease.

Absolute cell counts and the percentage of neutrophils were significantly increased in $\mathrm{CF}$ patients. If the $95 \%$ confidence interval was used as a cut-off point, $17 / 105 \mathrm{CF}$ patients had a normal percentage of neutrophils in pooled BAL samples, but only three also had a normal percentage of neutrophils in the first BAL aliquot.

Therefore, neutrophil dominated airway inflammation is more pronounced in the first, mainly bronchial, bronchoalveolar lavage sample suggesting that sequential analysis of bronchoalveolar lavage fluid may have a higher sensitivity to detect early inflammatory changes in $\mathrm{CF}$ patients.

Eur Respir J 2000; 15: 141-145.
Children's Hospitals of the Universities of *Essen, ${ }^{\#}$ Cologne, ${ }^{+}$Munich, ${ }^{* *}$ Hannover: \#\# Berlin, Germany. ${ }^{++}$Hygieneinstitut, University of Tübingen, Tübingen, Germany.

Correspondence: F. Ratjen

Children's Hospital, University of Essen Hufelandstr. 55

D-45122 Essen

Germany

Fax: 492017235983

Keywords: Airway inflammation bronchoalveolar lavage cystic fibrosis

Received: June 131999

Accepted after revision September 301999

Supported by a grant from the German cystic fibrosis foundation (Mukoviszidose e.V.) and by Hoffmann-La Roche, Germany.
Cystic fibrosis (CF) is an obstructive lung disease characterized by chronic productive cough and recurrent respiratory infections. Recent studies with bronchoalveolar lavage (BAL) have shown that neutrophil dominated airway inflammation is a common finding even in clinically stable patients as well as in infants, diagnosed by newborn screening, who lack clinical evidence of respiratory disease [1-3]. Whether this inflammatory process is directly related to the defect in the cystic fibrosis transmembrane regulator (CFTR) or secondary to bacterial infections is unclear and is the subject of an ongoing discussion [4-6].

The natural history of early airway inflammation in CF remains poorly defined. Histological data from patients with limited respiratory disease as well as lung function studies suggest that the disease process starts in the small airways rather than in the lung parenchyma $[7,8]$. The expression of the CFTR protein follows the same regional distribution as it is primarily expressed in bronchial tissue and not in alveoli $[9,10]$. BAL is a technique mainly used to assess processes involving the lung parenchyma, as most of the recovered cellular and noncellular material is obtained from this region of the respiratory tract $[11,12]$. Studies in children and adults without lung disease have shown that the first recovered BAL aliquot is of more bronchial origin and may therefore be of interest when studying diseases mainly involving the conducting air- ways $[13,14]$. So far, BAL studies of CF patients have used pooled specimens of the returned fluid $[1,2,5,6$, 13] which may not adequately reflect the changes seen in the airways, especially in patients with limited disease. To assess whether fractional analysis of BAL fluid may be a more sensitive way of detecting airway inflammation, the authors have studied BAL cytology in 105 clinically stable CF patients with good pulmonary function.

\section{Material and methods}

\section{Patients}

Patients included in this analysis were studied as a baseline assessment for the bronchoalveolar lavage for evaluation of anti-inflammatory treatment (BEAT) study which aimed to assess the natural course of airway inflammation in CF patients with normal lung function and its possible modulation by dornase alpha. The study population consisted of $105 \mathrm{CF}$ patients (53 female/52 male) aged 5-37 yrs (mean age \pm SD: $11.8 \pm 5.4$ yrs). Only 10 of these patients were older than $15 \mathrm{yrs}$ of age. The diagnosis of $\mathrm{CF}$ had been confirmed by repeated sweat test with chloride concentrations exceeding $60 \mathrm{mmol} \cdot \mathrm{L}^{-1}$. Genetic analysis for the 10 most prevalent CFTR mutations in Germany was available in 96 of the 105 patients (table 1). Patients were 
Table 1. - Mutation analysis of the study population

\begin{tabular}{lc}
\hline Genotype & $\mathrm{n}$ \\
\hline$\Delta$ F508 homozygeous & 66 \\
$\Delta$ F508 compound & 19 \\
Heterozygeous & 6 \\
Other known genotypes & 5 \\
Unidentified mutation & 9 \\
ND & \\
\hline
\end{tabular}

ND: not done.

eligible for this study if they were at least 5 yrs of age and had normal lung function defined by forced expiratory volume in one second (FEV1) $>80 \%$ predicted (table 2 ) [15]. Patients receiving anti-inflammatory treatment (ibuprofen, systemic or inhaled corticosteroids and $\alpha_{1}$-antitrypsin) as well as patients with evidence of allergic bronchopulmonary aspergillosis were not included in this study. All patients had to be free of acute respiratory infections and pulmonary exacerbations prior to entry in this study for at least 6 weeks. Patients were recruited in the five participating centres (Berlin, Cologne, Essen, Hannover and Munich, Germany) over a period of 15 months. The study was approved by the local Ethics Committees of all participating centres; written informed consent by both parents and/or the patients was obtained in all cases. Lung function tests were performed at least twice in the 3 months prior to entry of the study to confirm that patients were clinically stable.

\section{Bronchoalveolar lavage}

Bronchoalveolar lavage was performed via a flexible bronchoscope with an outer diameter of $3.5 \mathrm{~mm}$ in patients $<10$ yrs of age and a $4.9 \mathrm{~mm}$ diameter in older patients. Topical anaesthesia was achieved via inhalation of $2-4 \mathrm{~mL}$ of a $4 \%$ lignocaine solution prior to BAL and $1-4 \mathrm{~mL}$ of $2 \%$ lignocaine as needed while introducing the bronchoscope into the airways. Patients were sedated with midazolam $\left(0.2-0.3 \mathrm{mg} \cdot \mathrm{kg}\right.$ body weight $\left.{ }^{-1}\right)$ in two centres, a combination of midazolam and pethidin $(0.5 \mathrm{mg} \cdot \mathrm{kg}$ body weight $^{-1}$ ) in one centre and propofol (loading dose of 2 $\mathrm{mg} \cdot \mathrm{kg}$ body weight ${ }^{-1} 1$ and repeated doses of $10 \mathrm{mg}$ ) in one additional centre. In the remaining centre BAL was performed under general anaesthesia with nitrous oxideoxygen mixture with 2.5 volume (vol) percentage halothane. To standardize the BAL procedure, the first BAL

Table 2. - Pulmonary function parameters in per cent predicted for the population of cystic fibrosis

\begin{tabular}{ll}
\hline $\begin{array}{l}\text { Lung function parameter } \\
\% \text { predicted* [16] }\end{array}$ & Mean \pm SD \\
\hline FVC & $99 \pm 14 \%$ \\
FEV1 & $96 \pm 15 \%$ \\
MEF25\%VC & $77 \pm 34 \%$ \\
MEF25-75 & $91 \pm 46 \%$ \\
\hline
\end{tabular}

FVC: forced vital capacity; FEV1: forced expiratory volume in one second; $\mathrm{MEF} 25 \% \mathrm{VC}$ : maximal expiratory flow at $25 \%$ of the vital capacity; MEF25-75: maximal expiratory flow when $25-75 \%$ of the lung volume remains to be exhaled. *: per cent predicted values are taken from [16]. was supervized by one of the investigators (F. Ratjen) in all participating centres.

The bronchoscope was wedged in the lingula or one of its segments in all patients. BAL was performed as described before with $3 \mathrm{~mL} \cdot \mathrm{kg}$ body weight ${ }^{-1}$ normal saline warmed to body temperature [16]. In children weighing $<20 \mathrm{~kg}, 3 \times 1 \mathrm{~mL} \cdot \mathrm{kg}^{-1}$ of normal saline was instilled and immediately withdrawn by gentle manual suction. In children weighing $>20 \mathrm{~kg}$, BAL was performed in aliquots of $20 \mathrm{~mL}$ syringes up to a total volume of $3 \mathrm{~mL} \cdot \mathrm{kg}$ body weight ${ }^{-1}$. The first aliquot of the recovered BAL fluid was treated separately; all other samples were pooled for analysis.

Bacterial cultures were obtained on $2 \mathrm{~mL}$ of the first BAL fluid sample prior to filtration. Rather than using $10^{5}$ bacteria as a cut-off point, the authors have considered CF pathogens in BAL fluid to be of relevance regardless of bacterial counts, which is similar to the approach used in previous studies of CF patients $[1,2,5]$. The first and pooled samples were filtered through one layer of sterile gauze to remove mucous. BAL fluid was centrifuged at $500 \times g$ for $10 \mathrm{~min}$. The cell suspension of both the first and the pooled BAL sample was washed three times in Eagle's minimal essential medium (MEM) containing $0.2 \%$ bovine serum albumin (BSA) and $0.1 \%$ ethylene diamine tetra-acetic acid EDTA or in Hank's solution and resuspended in MEM. Bronchoalveolar cells were counted with a cell counter and cell viability was assessed by trypan exclusion. Differential cell counts were obtained from smears stained with May-Grünwald Giemsa. At least 600 cells were counted in each subject.

BAL cytology of both the first and the pooled sample were compared to reference values obtained with the same BAL protocol in a population of 48 children aged 3-15 yrs undergoing BAL during elective surgery for nonpulmonary illnesses [16].

\section{Statistics}

All data were tested for normal distribution with the Kolmogorov-Smimov test. Results were expressed as mean \pm SD. The median is also reported for all data. Because of the nonparametric distribution of most BAL parameters, differences between the populations were assessed with the Wilcoxon Mann-Whitney U-test. A p-value of $<0.01$ was considered statistically significant.

\section{Results}

The bacterial pathogens cultured from BAL fluid in the CF patient population are displayed in table 3. Seventyfive of 105 patients had bacteria in BAL fluid with Staphylococcus aureus being the predominant pathogen in the lower airways. However, 30 patients were colonized with Pseudomonas aeruginosa. Co-colonization of $S$. aureus and P. aeruginosa was found in 11 cases; of $S$. aureus and Haemophilus influenzae in 16 cases.

The BAL cytology is shown in table 4. Overall total cell counts were significantly higher in CF compared to the reference population. The percentage of neutrophils as well as total cell counts were increased both in the first and pooled BAL sample (table 4). There was a significant 
Table 3. - Microbiology of bronchoalveolar lavage (BAL) fluid

\begin{tabular}{lr}
\hline Pathogens & $\mathrm{n}$ \\
\hline Pseudomonas aeruginosa & 30 \\
Staphylococcus aureus & 51 \\
Haemophilus influenzae & 21 \\
Other bacteria & 7 \\
Aspergillus fumigatus & 4 \\
Candida species & 6 \\
None & 30 \\
\hline
\end{tabular}

correlation $(\mathrm{r}=0.58, \mathrm{p}<0.001)$ between the percentage of neutrophils in the first and the pooled sample for $\mathrm{CF}$ patients, although marked differences were observed in individual cases (fig. 1). The percentage of lymphocytes and macrophages were significantly lower $(\mathrm{p}<0.001)$ in both the first and the pooled BAL sample, but absolute lymphocytes counts were not different from the control group. Since the percentage of neutrophils in both the first and pooled BAL sample followed a normal distribution after $\log$ transformation, the $95 \%$ confidence interval of the reference population was chosen as a cut-off point to define the normal range. Using this approach 17/105 CF patients had a normal percentage of neutrophils in pooled BAL samples, but only three of these also had a normal percentage of neutrophils in the first BAL sample.

There was no significant correlation between the percentage of neutrophils in BAL fluid and age or lung

Table 4. - Bronchoalveolar lavage (BAL) cytology in cystic fibrosis (CF) patients compared to the reference population [16].

\begin{tabular}{|c|c|c|c|c|}
\hline \multirow[t]{2}{*}{ Cell type } & \multirow[t]{2}{*}{ Sample } & $\mathrm{CF}$ & $\begin{array}{l}\text { Reference } \\
\text { population }\end{array}$ & p-value \\
\hline & & $\begin{array}{l}\text { mean } \pm \mathrm{SD} \\
\text { (range; } \\
\text { median) }\end{array}$ & $\begin{array}{l}\text { mean } \pm \text { SD } \\
\text { (range; } \\
\text { median) }\end{array}$ & $\begin{array}{c}\text { Wilcoxon } \\
\text { test }\end{array}$ \\
\hline \multirow[t]{2}{*}{ Macrophages } & first & $\begin{array}{c}41 \pm 29 \\
(0-94 ; 40)\end{array}$ & $\begin{array}{c}84 \pm 11 \\
(55-99 ; 87)\end{array}$ & $<0.0001$ \\
\hline & pooled & $\begin{array}{c}63 \pm 23 \\
(2-96 ; 65)\end{array}$ & $\begin{array}{c}81 \pm 13 \\
(35-96 ; 84)\end{array}$ & $<0.0001$ \\
\hline Lymphocytes & $\begin{array}{l}\text { first } \\
\text { pooled }\end{array}$ & $\begin{array}{c}5 \pm 6 \\
(0-31 ; 3.5) \\
8 \pm 7\end{array}$ & $\begin{array}{c}10 \pm 8 \\
(0-36 ; 8) \\
16 \pm 12\end{array}$ & $<0.0001$ \\
\hline \multirow{3}{*}{ Neutrophils } & first & $\begin{array}{c}(0-39 ; 5.5) \\
52 \pm 30\end{array}$ & $\begin{array}{c}(2-61 ; 12.5) \\
4 \pm 5\end{array}$ & $<0.0001$ \\
\hline & & $(0-100 ; 56)$ & $(0-19 ; 2)$ & $<0.0001$ \\
\hline & pooled & $\begin{array}{c}29 \pm 23 \\
(0-91 ; 26)\end{array}$ & $\begin{array}{c}2 \pm 3 \\
(0-17 ; 1)\end{array}$ & $<0.0001$ \\
\hline \multirow[t]{2}{*}{ Eosinophils } & first & $\begin{array}{c}0.6 \pm 0.9 \\
(0-3.4 ; 0.1)\end{array}$ & $\begin{array}{c}0.7 \pm 1.4 \\
(0-7.2 ; 0.2)\end{array}$ & 0.57 \\
\hline & pooled & $\begin{array}{l}0.5 \pm 0.8 \\
(0-5 ; 0)\end{array}$ & $\begin{array}{c}0.4 \pm 0.6 \\
(0-3.6 ; 0.2)\end{array}$ & 0.53 \\
\hline \multirow[t]{2}{*}{$\begin{array}{l}\text { Total cells } \\
\times 10^{4} \cdot \mathrm{mL}^{-1}\end{array}$} & first & $\begin{array}{c}82 \pm 155 \\
(0.1-920 ; 33)\end{array}$ & $\begin{array}{c}6.5 \pm 4 \\
(1.2-70 ; 4)\end{array}$ & $<0.0001$ \\
\hline & pooled & $\begin{array}{c}34 \pm 44 \\
(0.1-210 ; 19)\end{array}$ & $\begin{array}{c}10.3 \pm 11 \\
(0.5-57 ; 7.3)\end{array}$ & $<0.0001$ \\
\hline \multirow[t]{2}{*}{ Recovery \% } & first & $\begin{array}{c}32 \pm 15 \\
(5-70 ; 30)\end{array}$ & $\begin{array}{c}36 \pm 13 \\
(13-59 ; 36)\end{array}$ & 0.08 \\
\hline & pooled & $\begin{array}{c}64 \pm 21 \\
(10-99 ; 70)\end{array}$ & $\begin{array}{c}65 \pm 18 \\
(22-96 ; 69)\end{array}$ & 0.97 \\
\hline
\end{tabular}

Cell types are mentioned in percentages; total cells in absolute numbers.

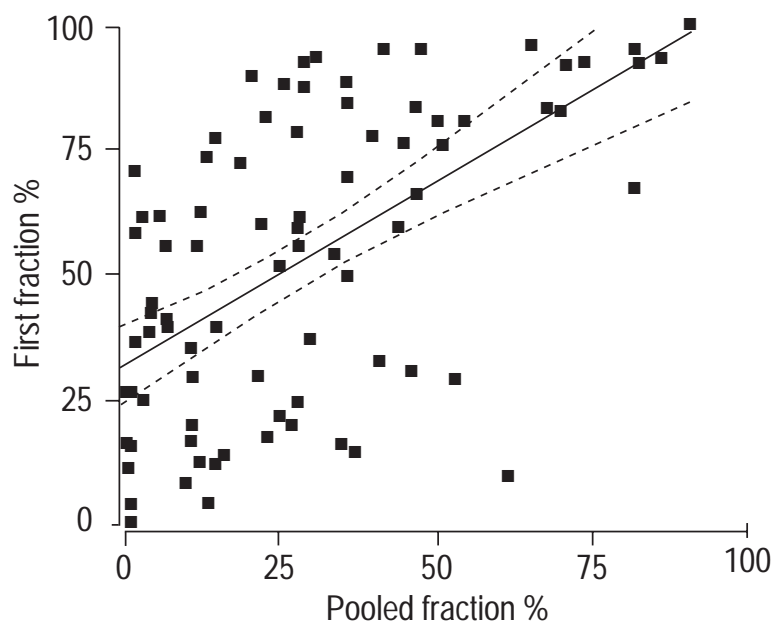

Fig. 1. - Linear regression analysis of the first versus the pooled bronchoalveolar lavage (BAL) fraction in cystic fibrosis (CF) patients. Each symbol represents one individual. Despite a significant positive correlation between the two parameters, considerable variability was observed in individual patients. - : regression lines; $----: 95 \%$ confidence intervals. $\mathrm{r}=0.58, \mathrm{p}<0.001$.

function parameters (forced vital capacity (FVC), FEV1 and maximal expiratory flow at $25 \%$ of the vital capacity (MEF 25\%VC) and there was no difference in neutrophils between CF patients with normal MEF $25 \% \mathrm{VC}$ and those with reduced values. There was no correlation between neutrophil percentages and age in CF patients and no differences were observed between patients studied under general anaesthesia and those receiving sedatives. Patients in whom bacteria were found in BAL fluid had a significantly higher percentage of neutrophils in both the first and pooled BAL sample when compared to those with negative bacterial cultures (fig. 2). When $P$. aeruginosa positive and negative patients were compared, there was no difference in either total cell counts or the percentage of individual cell populations of both the first and the pooled BAL sample.

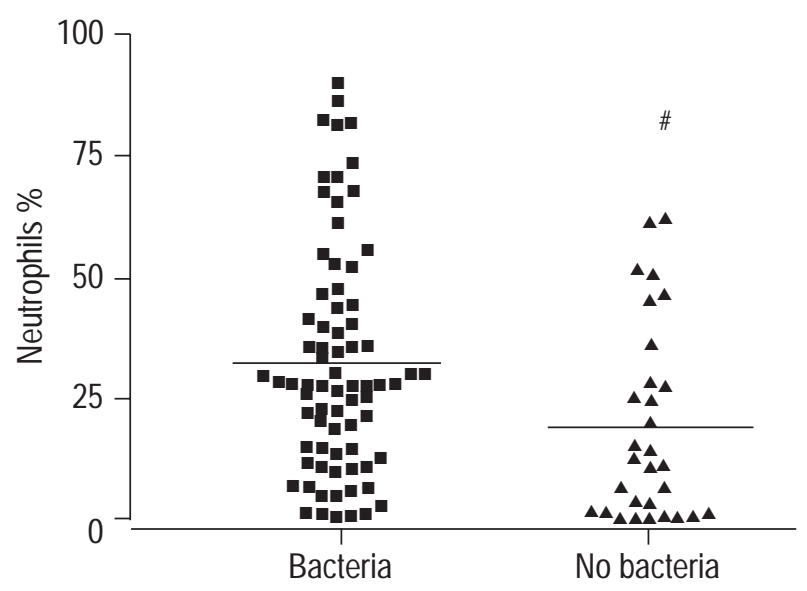

Fig. 2. - Percentage of neutrophils in pooled bronchoalveolar lavage (BAL) samples in cystic fibrosis (CF) patients with and without bacteria in BAL cultures. Each symbol represents one individual; the horizontal lines represent the mean of each group. The percentage of neutrophils was significantly higher in CF patients with positive bacterial cultures. ${ }^{\#}$ : $\mathrm{p}<0.004$, Wilcoxon test. 


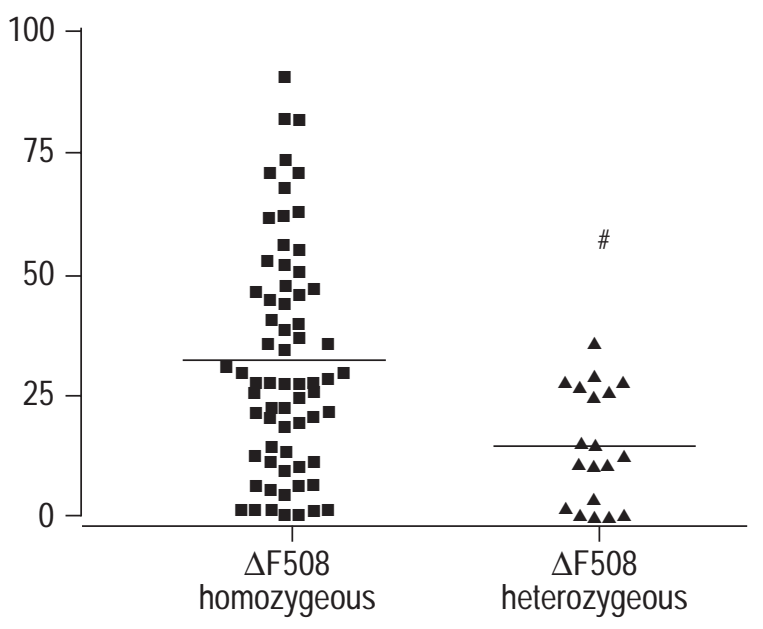

Fig. 3. - Percentage of neutrophils in pooled bronchoalveolar (BAL) samples in cystic fibrosis (CF) patients homozygous and compound heterozygous for the $\Delta \mathrm{F} 508$ mutation. Each symbol represents one individual; the horizontal lines represent the mean of each group. The percentage of neutrophils was significantly higher in $\Delta F 508$ homozygous CF patients. ${ }^{\#}$ : $\mathrm{p}<0.003$. Wilcoxon test.

As illustrated in the Material and methods section, most patients were homozygous for the $\Delta \mathrm{F} 508$ mutation followed by a group of patients compound heterozygeous for $\Delta$ F508 (table 1). These two groups did not differ in terms of lung function and the percentage of patients positive for bacteria in BAL fluid. The absolute number of patients with other genotypes was too low to allow for statistical analysis of these groups. However, CF patients homozygous for $\Delta \mathrm{F} 508$ had a significantly higher percentage of neutrophils in BAL fluid compared to those compound heterozygous for $\Delta \mathrm{F} 508$ (fig. 3 ).

\section{Discussion}

The present study in a large population of CF patients confirms previous reports that neutrophil dominated inflammation is common even in patients with normal lung function and few respiratory symptoms. In contrast to previous studies of BAL in CF patients with mild lung disease, the current authors have performed sequential analysis of BAL samples separating the first, mainly bronchial, fraction which may be of greater relevance for airway diseases than subsequent, more alveolar, samples. The authors have previously shown in children without lung disease that the first fraction contains more neutrophils and less lymphocytes than pooled BAL specimens which is consistent with a more bronchial origin of the sample [16]. Here the authors could show that in CF patients with mild lung disease, the neutrophil dominated inflammation is more pronounced in the first fraction of BAL. The higher rate of BAL neutrophil counts exceeding the $95 \%$ confidence interval of the reference population is in accordance with the concept that $\mathrm{CF}$ is primarily a bronchial disease. Therefore, assessing the first fraction of a BAL may be more representative for $\mathrm{CF}$ airway inflammation, especially in CF patients with limited disease where cytology of the pooled BAL may still appear to be within the normal range.

Similar to the findings by ARMSTRONG and coworkers [5, 6], the current authors could demonstrate that CF patients with pathogens in their lower respiratory tract have a higher percentage of neutrophils in BAL fluid. However, neutrophil cell counts in the current study population were also elevated in patients with negative respiratory cultures. This could illustrate both an increased inflammatory response to prior respiratory infections or a proinflammatory milieu generated by the CFTR defect.

Studies using a $P$. aeruginosa beads model for pulmonary inflammation have demonstrated an augmented inflammatory response to the infection in $\mathrm{CF}$ mice as compared to control animals [17]. Likewise NoAH et al. [18] have shown that the response of pro-inflammatory cytokines in BAL fluid is augmented in $\mathrm{CF}$ individuals when compared to non-CF children with similar numbers of bacterial pathogens. Whether this is an intrinsic defect related to the CFTR mutation has yet to be elucidated. Limited evidence from studies in infants would suggest that the predominance of neutrophils in BAL fluid persists throughout infancy and early childhood [19]. The present study supports the concept that neutrophil dominated inflammation in $\mathrm{CF}$, although more pronounced in the presence of airway infection, is also present in the absence of bacterial pathogens.

This study found a significant difference in the percentage of neutrophils between patients homozygous for $\Delta$ F508 and those compound heterozygous for this mutation. Genotyping was only performed for the 10 most frequent mutations and the second mutation was unidentified in most of these patients. Nevertheless, it can be speculated that $\Delta \mathrm{F} 508$ heterozygous patients are more likely to have residual CFTR function which may have a positive effect on the inflammatory process within the airways. Larger series of patients have not found clinical differences in lung function, rate of $P$. aeruginosa infection or rate of pancreatic insufficiency between patients homoor heterozygous for $\Delta \mathrm{F} 508$ [20]. Likewise, the authors did not observe any significant difference in these clinical data as well as the number of patients with bacteria in the lower respiratory tract between the two groups in this study.

It is therefore speculated that bronchoalveolar lavage is capable of delineating subtle changes within the lung that are not detected by the techniques mentioned above. Future studies should link techniques reflecting the inflammatory process in the lung such as bronchoalveolar lavage with methods assessing cystic fibrosis transmembrane regulator function.

Additional members of the Bronchoalveolar lavage for the evaluation of Anti-inflammatory treatment BEATstudy group. $\mathrm{U}$. Wahn (Berlin), S. van Koningsbruggen (Cologne), M. ElterSchulz (Essen), P. Tinschmann (Frechen), J. Freihorst, H. von der Hardt (Hannover), K. Behr (Munich). The BEAT study was initiated and organized by K. Paul (Berlin).

Acknowledgement. The authors would like to thank U. Schneider for the assessment of differential cell counts.

\section{References}

1. Konstan MW, Hilliard KA, Norvell TM, Berger M. Bronchoalveolar lavage findings in cystic fibrosis patients with stable, clinically mild lung disease suggest ongoing 
infection and inflammation. Am J Respir Crit Care Med 1994; 150: 448-454.

2. Khan TZ, Wagener JS, Bost T, Martinez J, Accurso FJ, Riches DW. Early pulmonary inflammation in infants with cystic fibrosis. Am J Respir Crit Care Med 1995; 151: 1075-1082.

3. Balough K, McCubbin M, Weinberger M, Smits W, Ahrens R, Fick R. The relationship between infection and inflammation in the early stages of lung disease from cystic fibrosis. Pediatr Pulmonol 1995; 20: 63-70.

4. Cantin A. Cystic fibrosis lung inflammation: early, sustained and severe. Am J Respir Crit Care Med 1995; 151: 939-941.

5. Armstrong DS, Grimwood K, Carzino R, Carlin JB, Olinsky A, Phelan PD. Lower respiratory infection and inflammation in newly diagnosed cystic fibrosis. $B M J$ 1995; 310: 1571-1572.

6. Armstrong DS, Grimwood K, Carlin JB, et al. Lower airway inflammation in infants and young children with cystic fibrosis. Am J Respir Crit Care Med 1997; 156: 1197-1204.

7. Bedrossian CW, Greenberg SD, Singer DB, Hansen JJ, Rosenberg HS. The lung in cystic fibrosis. A quantative study including prevalence of pathologic findings among different age groups. Hum Pathol 1976; 7: 195-204.

8. Fox WW, Bureau MA, Taussig LA, Martin RR, Beaudry $\mathrm{PH}$. Helium flow-volume curves in the detection of early small airway disease. Pediatrics 1974; 54: 293-299.

9. Tizzano EF, O'Brodovich H, Chitayat D, Benichou JC, Buchwald M. Regional expression of CFTR in developing human respiratory tissues. Am J Respir Cell Mol Biol 1994; 10: 355-362.

10. Engelhardt JF, Zepeda M, Cohn JA, Yankaskas JR, Wilson JM. Expression of the cystic fibrosis gene in adult human lung. J Clin Invest 1994; 93: 737-749.
11. Klech H, Hutter C, eds. Clinical guidelines and indications for bronchoalveolar lavage (BAL). Report of the European Society of Pneumology Task Group on BAL. Eur Respir J 1990; 3: 937-974.

12. Henderson AJW. Bronchoalveolar lavage. Arch Dis Child 1994; 70: 167-169.

13. Birrer P, McElvaney NG, Rudeberg A, et al. Proteaseantiprotease imbalance in the lungs of children with cystic fibrosis. Am J Respir Crit Care Med 1994; 150: 207-213.

14. Rennard SI, Ghafouri MO, Thompson AB, Linder J, Vaughan W, Jones K. Fractional processing of sequential bronchoalveolar lavage to separate bronchial and alveolar samples. Am Rev Respir Dis 1990; 141: 208-217.

15. Knudson RJ, Slatin RC, Lebowitz MD, Burrows B. The maximal expiratory flow volume curve. Normal standards, variability and effects of age. Am Rev Respir Dis 1976; 113: 587-600.

16. Ratjen F, Bredendiek M, Brendel M, Meltezer J, Costabel U. Differential cytology of bronchoalveolar lavage fluid in normal children. Eur Respir J 1994; 7: 1865-1870.

17. Heeckeren A, Walenga R, Konstan M, Bonfield T, Davies PB, Ferkol T. Excessive inflammatory response of cystic fibrosis mice to bronchopulmonary infection with Pseudomonas aeruginosa. J Clin Invest 1997; 100: 28102815.

18. Noah TL, Black HR, Cheng PW, Wood RE, Leigh MW. Nasal and bronchoalveolar lavage fluid cytokines in early cystic fibrosis. J Infect Dis 1997; 175: 638-647.

19. Wagener JS, Sontag MK, Accurso FJ. Long term stability of airway inflammation in infants and young children with cystic fibrosis. Pediatr Pulmonol 1997; Suppl. 14: 420A.

20. The cystic fibrosis genotype-phenotype consortium. Correlation between genotype and phenotype in patients with cystic fibrosis. N Engl J Med 1993; 329: 1308-1313. 